\title{
Investigating EFL Learners' Perceptions of Collaborative Writing
}

\author{
Majed O. Abahussain ${ }^{1}$ \\ ${ }^{1}$ Department of English, College of Education, Majmaah University, Majmaah, Saudi Arabia \\ Correspondence: Majed O. Abahussain, Department of English, College of Education, Majmaah University, \\ Majmaah, Saudi Arabia. E-mail: m.abahussain@mu.edu.sa
}

Received: January 8, 2020 Accepted: February 21, 2020 Online Published: March 12, 2020

doi:10.5539/ijel.v10n3p32 URL: https://doi.org/10.5539/ijel.v10n3p32

\begin{abstract}
Although pair and group work are commonly applied in English language classrooms, research investigating EFL learners' perceptions of collaborative writing (CW henceforth) is still limited. The present study explores EFL students' attitudes and perceptions toward CW. The study involved $30 \mathrm{~L} 2$ students enrolled in a writing course at one of the largest universities in Saudi Arabia. The course was divided into two parts: individual writing (IW) for the first month (four weeks) and collaborative writing for the second month (four weeks). The study uses a within-groups mixed methods design whereby the same group of students received both the individual writing and collaborative writing assignments for exploring participants' attitudes toward collaborative writing as compared to their views toward individual writing. The same self-report survey (6-point Likert-scale) was used two times (after each writing condition) to determine the participants' views of each writing condition. In addition, semi-structured interviews were conducted to gain qualitative insights while exploring the participants' views toward the two writing conditions they experienced as well as to find out the benefits and challenges they faced. Results show that participants reported the effectiveness of CW significantly higher than individual writing. The analyses reveal a statistically significant difference where ratings of $\mathrm{CW}$ were higher compared to IW, indicating helpfulness of $\mathrm{CW}$ in enhancing not only their writing skills but also their learning of all four English language skills. Despite some reservations, the majority of the participants were supportive of the $\mathrm{CW}$ experience.
\end{abstract}

Keywords: collaborative writing, L2 writing, individual writing, essay writing

\section{Introduction}

Several researchers (e.g., Daiute, 1986; Kuiken \& Vedder, 2002; Shehadeh, 2011; Storch, 2005, 2011; Storch \& Wigglesworth, 2007) argue that students should collaborate throughout the writing process. This collaboration should not be confined to one stage of writing, but rather the students should have joint responsibility throughout the stages: brainstorming, composing, and revising. As Weissberg (2006) argues, "engaging students in dialogue about their writings can allow them more opportunity, not only to clarify and defend their meanings, but also build a greater sense of ownership over their texts" (p. 74). Hence, this sense of joint responsibility and "positive interdependence" (Jacobs, 2004, p. 74) among the collaborators encourages them to contribute to decision making on all aspects of writing: content, structure, and language. And therefore, this collaboration enables L2 learners to use their target language and pool their strengths and weaknesses, which enables them to co-construct greater knowledge.

Collaborative writing (CW henceforth) is viewed as beneficial for language learners, as students learn more about writing by talking and listening to their peers (Bruffee, 1973; Dobao, 2012; Shehadeh, 2011; Speck, 2002; Storch, 2005). As Biria and Jafari (2013) state, "collaborative writing can be used as a pedagogical tool to encourage more classroom interaction among learners where they are accustomed to individual work" (p. 2434). Moreover, in CW, the four English language skills are integrated; that is, EFL learners discuss ideas, listen to one another, read, and revise their shared text.

In the context of EFL, CW is not just the jointly produced text, but also collective cognition where two or more people reach insights that they could not have reached alone (Stahl, 2006; Storch, 2013). This collective cognition offers an opportunity to learn new vocabulary and improved ways of expressing ideas, as well as share ideas with one another. During collaboration, EFL learners receive feedback from their peers as they compose and revise the text together. Therefore, $\mathrm{CW}$ enables learners to develop their cognitive ability and expand their 
language learning.

Some studies have suggested that all language processes (i.e., listening, speaking, reading, and writing) are synergistic (Speck, 2002; Whitehead, 2004). Additionally, according to Harste (1984), learning a language relies on its use during social negotiation and hypothesis testing, as these elements enable the learner to gradually attain semantic competence. Most children learn their first language through listening and speaking to their parents, and learn literacy skills-reading and writing-in schools. Usually, these literacy skills cannot be learned independently or in the home; they are taught in schools (Prior, 2006). However, the teaching approach of reading and writing plays a significant role in learning how to write. In some EFL contexts, especially in Saudi Arabia, the traditional teaching method is still being used. This method focuses on explicit instruction of grammatical analysis of the target language while the teacher controls the learning environment. The teacher is the main source of knowledge, while students passively receive the information (in the form of lectures). This is considered a teacher-centered classroom. The traditional teacher view is that it is the teacher who causes learning to occur. This approach could cause individual differences among the students, where some of them have more knowledge about the target language than others.

Unfortunately, while there are many effective pedagogical methods for writing instruction that have been well established in EFL/ESL contexts, the teaching of writing in Saudi colleges seems to be neglected or given little importance (AlKhairy, 2013). In Saudi EFL classrooms, students learn writing as an isolated activity through teacher-directed prompts and reading-related assignments. As such, Ansari's (2012) research on "Teaching of English to Arab students: Problems and remedies" claimed that more than 50\% of Saudi students do not know how to write in English. Moreover, Huwari and Al-Khasawneh (2013) confirmed, "Arab learners of English which include Saudi Arabia encounter major problems in writing" (p. 1). Therefore, this study will investigate the teachers' and students' perceptions of the CW approach at Qassim University. Students' preferences are important for curriculum designers, textbook planners, and EFL writing instructors. The researcher will explore whether the collaborative approach is an effective teaching method from the perspectives of teachers and learners.

\section{Literature Review}

In the field of L2 writing, the learner-centered approach (e.g., CW) manifested itself as an emphasis on learners' attitudes toward and perceptions of L2 writing practices, or in Johns' (1991) terminology, their "personal theories" of literacy. Since these theories influence L2 learners' writing behavior and shape their learning, it is essential for writing instructors to understand how they are formed and how they develop (Petric, 2002). For L2 learners, teaching/learning strategies play a significant role in shaping their learning. Some students are visual learners, whereas others are audio learners. Likewise, some students may be extroverts, whereas others are introverts, and so on. Despite students' differences in their learning styles, however, I do believe that positive attitudes toward a certain writing technique can lead to its subsequent positive use. It is, therefore, important to gain insight into learners' personal theories of L2 writing pedagogy and their perceptions of different writing conditions (i.e., individual vs. collaborative) in order to come up with more effective methods and approaches in teaching writing that, at the same time, the students find more useful and enjoyable.

There is a long tradition of research into attitudes (e.g., Horwitz, 1999; Kennedy \& Kennedy, 1996; Leki, 1995) focusing on the area of learners' individual differences and learning strategies as factors that affect L2 learning. This line of research has shown that there is a correlation between attitudes and achievement, and that attitudes have an indirect impact on achievement (learning). Petric (2002), for instance, confirmed that "attitudes towards learning writing may be based on beliefs about language learning strategies in general" (p. 11).

It is important to mention that Petric's (2002) findings in his study on learners' attitudes toward L2 writing have also shown that "attitudes determine learning behavior in a complex way, but also emerge as an outcome of language learning" (p. 11). That is, learners' beliefs are not only grounded in underlying attitudes, but are also formed or changed in light of new experiences. In other words, when an individual learner has a positive attitude toward a certain writing strategy, learning will be successful because attitudes influence behavior and are key indicators of the results. Hence, attitudes influence a learning process significantly.

L2 learners' preferences, including the types of learners and their learning strategies, are important for instructors to know. Storch (2013) stated that "learners bring to the classroom a complex cluster of attitudes, expectations and preferences, all of which form significant contributory factors in the language learning process" (p. 93). Other researchers have also recognized the importance of learners' attitudes to the success of L2 learning (Dörnyei \& Kormos, 2000; Shehadeh, 2011; Storch, 2005). Their studies have shown that learners' engagement in certain activities may be affected by whether they believe that an activity is likely to facilitate their language 
learning. In addition, in a study on learners' uptake of written corrective feedback, Storch and Wigglesworth (2007) found that learners' attitudes on the type of feedback given impacted how much of the feedback they heeded. This research raised the importance of taking learners' perspectives into consideration when teachers attempt to understand learners' attitudes on language learning.

Without a doubt, learners' beliefs and perceptions shape their attitudes, performance, and inclination to act in certain ways (Storch, 2013). If learners believe, based on their experiences, that one way of learning a language is by practicing using the language, they are likely to be positively predisposed toward participating in any tasks that require interaction and communication in the L2. As a result, they may not have any difficulties accepting and participating in the types of activities associated with the communicative approach, such as collaborative group work.

Language learners' beliefs toward learning a certain language may be influenced by the activities they are exposed to in learning the language and/or the activities teachers use in the classroom. Green (1993) conducted a study using a large-scale survey on 263 EFL students to rank a list of classroom activities and practices based on their frequency of exposure, level of enjoyment, and perceived helpfulness for language learning. The study found a weak correlation between the level of enjoyment and helpfulness and learners' previous experiences with these activities. That is, the learners were willing to rank an activity highly even if they had very little experience with the activity. These findings suggest that students' preconceived beliefs affect their judgments of the enjoyment and the effectiveness of classroom activities.

Peng (2011) investigated the changes of EFL learners' beliefs about English teaching and learning since their enrollment. In the seven-month-long study, participants experienced different teaching approaches and a number of classroom activities. Based on the data collected through interviews, classroom observation, and students' daily learning journals, the findings revealed that changes in beliefs are context-responsive; the learners shape their beliefs according to the nature of the classroom's activities, assessment practices, level of enjoyment, and perceptions of progress. The findings also showed that learners held positive attitudes toward oral communicative activities (collaborative group work), which they found more authentic, enjoyable, and conducive to their language learning. The researcher concluded that learners perceived the communicative approach (group work) not only as an effective means to learn a language, but also as a means to maintain their interest and motivation. In addition, this study suggests that when an activity (collaborative group work) is perceived by EFL learners as meaningful and enjoyable, they are more encouraged to participate actively in the group work discussion.

In a similar study of 16 Thai EFL students, McDonough (2004) examined whether learning opportunities attributed to small group activities occurred in an intact classroom, and whether participants who actively participated in group work activities showed any improvement in the target language. He found that the learners showed improvement in the use of the target language after engaging in collaborative group work, and most of them found group work conducive to improving their grammatical knowledge. Even though some students in the study expressed their concerns over learning possibly incorrect grammar from their peers, analysis of the group work discussion showed that these students still provided one another with useful and grammatically correct feedback.

From a pedagogical perspective, it is important to know, based on learners' attitudes and perceptions, which activities they find useful, enjoyable, and attributable to their language learning in order for instructors to subsequently plan their classroom activities as well as to review or change their teaching of writing activities. In other words, it is essential for teachers, writing course designers, and textbook planners to recognize students' perspectives, perceptions, experiences, and attitudes of classroom activities (such as group work) in deciding what activities to focus on and what to avoid. In fact, many scholars have emphasized the importance of students' perspectives and have called for writing teachers, writing course designers, and language tutors to take the students' perspectives into account in a more informed way. Furthermore, studies that investigated L2 learners' attitudes on collaborative group or pair work showed that learners preferred to work in groups (e.g., Green, 1993; Littlewood, 2011; Mishra \& Oliver, 1998; Trinder, 2013), especially in communicative activities that required them to work in small group or pairs. Nevertheless, these studies on students' perceptions and attitudes are still rare, and there is a need for more of such research.

\subsection{Collaborative Writing in the L2 Context}

In the ESL/EFL context, studies investigated learners' perceptions of CW activities. One of the first studies to address this issue was by Storch (2005). Storch collected her data from 23 adult ESL learners during a writing course. In this writing class, 5 participants completed a writing task individually, while 18 students worked in 
pairs. The participants were interviewed after completing their writing tasks. Most students who worked in pairs (16 out of 18) expressed their positive attitudes about the experience, except two participants who had some reservations. According to the researcher, these two students felt their pair work was effective for oral interaction rather than writing activities. These two Japanese ESL students believed that writing is a solitary act and felt that working in pairs made it harder for them to concentrate and agree with their partners. They also reported that they did not want to lose face due to their limited level of English proficiency. Moreover, if they were obliged to work in pairs, they would prefer to self-select their partners. On the other hand, the other 16 students mentioned that $\mathrm{CW}$ provided them with an opportunity to discuss writing, learn from each other, share ideas, and learn how to best express their ideas in writing. They also said that they improved their grammatical accuracy as well as learned new vocabulary words. Storch concluded that collaboration offered learners an opportunity to pool their ideas and provide feedback to each other.

Shehadeh (2011) conducted a longitudinal investigation into the effectiveness of CW in an EFL writing classroom. The participants of his study were divided into two groups to complete the same writing assignments. One group worked individually, while the other worked in pairs. Shehadeh embarked on finding out whether or not CW had any effect on learners' quality of writing after engaging in such activities. The study lasted for 16 weeks and included pre- and post-tests. The study involved 38 college students who had low-intermediate levels of proficiency in English. A holistic rating procedure was used to rate the students' writing. The findings showed that $\mathrm{CW}$ had a significant effect on students' writing in regard to content, organization, and vocabulary. Shehadeh also administered questionnaires after 16 weeks of CW sessions. Most students who worked in groups reacted positively to their experience. Although $\mathrm{CW}$ activity was new to them, they felt that it contributed to their language development. Moreover, some of these students reported that $\mathrm{CW}$ activities helped them not only with their writing skills, but also with their speaking skills, because they used the language during their discussion, as well as their self-confidence.

To gain a deeper understanding of students' attitudes toward writing, Dobao and Blum (2013) investigated EFL learners' attitudes on pair and small group writing as well as learners' perceptions of the learning value of CW. There were $55 \mathrm{EFL}$ students participating in the study. These learners were divided into two sets: one set consisting of pairs and another set consisting of four students per group. The researchers examined the students' reaction to $\mathrm{CW}$ tasks and analyzed their preferences, not only between individual and collaborative writing, but also between pairs and the groups of four members. The researchers examined the learners' preferences and how these preferences were influenced by their engagement. The researchers also analyzed the learners' perceptions of $\mathrm{CW}$ activities as an approach to English language learning. The findings of this study showed that the students reacted positively to the experience of $\mathrm{CW}$. Participants who worked in pairs commented that they found it helpful because it offered them a chance to participate actively. Students who worked in groups of four reported that there were more ideas to discuss and knowledge to share, and therefore, it was an opportunity to improve their English writing. Only 4 out of 55 participants reported that they would have preferred to work individually. The researchers concluded CW has an impact on both the grammatical and lexical accuracy of their texts.

Studies investigating the effect of CW and IW on language learning using a pre- and post-test research design are still few (e.g., Kim, 2008; Kuiken \& Vedder, 2002; Nassaji \& Tian, 2010; Reinders, 2009). These studies used language-focused tasks to track students' improvement on language learning. The studies showed an advantage on collaboration on learners' language learning and writing skills in particular. However, an exploration of the literature proved that there is no study that has been conducted to gauge the same group of students' preferences for CW as compared with individual writing in Saudi college EFL students. Thus, this study will gauge students' perceptions of CW compared with IW. The students will experience IW for the first month and CW for the second month. Then, they will be surveyed after each writing condition to track their opinions across time. The researcher will investigate whether the students are able to recognize the benefits of writing collaboratively or individually as well as if their experience influences their perceptions and if they are aware of the learning value of $\mathrm{CW}$. By using a Likert-scale questionnaire, the researcher will look at how the learners' preferences may have been influenced by their engagement in CW vis-à-vis IW.

\section{Research Questions}

1) What are the students' ratings of IW assignments with regard to improving their writing skills? And what are their ratings of IW assignments with regard to improving their English language skills?

2) What are the students' ratings of $\mathrm{CW}$ assignments with regard to improving their writing skills? And what are their ratings of $\mathrm{CW}$ assignments with regard to improving their English language skills?

3) After having the opportunity to engage in CW assignments, what are students' attitudes toward CW? 
4) Judging from students' perceptions, what are the perceived benefits and challenges of CW for EFL learners? What difficulties do they experience when engaging in CW?

\section{Methodology}

\subsection{Participants}

A total of 30 full-time second-year students majoring in English (4-year diploma) participated in the present study. The English program that they were taking at the university is a 4-year program of English courses since the students are expected to become EFL instructors at elementary schools upon graduation. The students' ages ranged between 20-22 years, and they are considered to have an intermediate level of English proficiency. The participants were all Saudi males and share Arabic as their first language.

The program participants were enrolled in consists of eight levels of English (each level is a 3-month semester except the summer semester, which is 2 months long). Level 4 is the last level of the second year, and the students were considered to have intermediate English language proficiency. Participants have an intermediate level by this point (Level 4) because they have advanced in the program. They had been admitted to the university based on their placement examination scores, which are considered as the program's entrance exam. Their scores on the placement examinations ranged from 100 to 150 out of 900 scores (roughly equal to 1.5-2.5 on the IELTS [International English Language Testing System]). The university considered them to be intermediate learners.

\subsection{Research Design and Procedure}

The study used a within-groups design whereby the same group of students received both the IW and CW assignments. The study also used a mixed-methods research design to explore participants' attitudes toward collaborative writing as compared to their views toward individual writing. A self-report survey (6-point Likert scale) was used to investigate learners' perceptions of CW. Also, semi-structured interviews were conducted to gain qualitative insights while exploring the participants' views toward the two writing conditions they experienced as well as to find out the benefits and challenges they faced. This research paradigm was expected to yield new insights into what EFL learners think of individual and collaborative writing and how these two different writing assignments help them with their language learning and writing skills.

The course was divided into two parts: individual writing for the first month (4 weeks) and collaborative writing for the second month (4 weeks). As mentioned earlier, the intervention of $\mathrm{CW}$ occurred within the same group and was taught by the same instructor. Given the level of the participants' English language proficiency, the focus of writing tasks was at the essay level. Prior to taking this Level 4 writing course, participants had previously taken three writing courses in the first three levels. The Level 1 writing course was a basic writing course where students were introduced to sentence types and structure. In the Level 2 writing course, students were introduced to academic writing where they wrote short paragraphs. In the Level 3 course, students were trained to write different types of paragraphs with unity and coherence. At the fourth and final level, the focus of the writing course was at the essay level where students were trained to write different types of essays. All participants experienced each type of writing condition (individual vs. collaborative) for the same amount of time (i.e., they followed the same writing processes for each writing condition).

The researcher of the present study designed the syllabus for the writing course. Given the aim of the present study, the course was divided into two different writing conditions where students would experience both of the conditions (individual and collaborative writing) for equal amounts of time. For the first month, the students practiced writing individually, whereas for the second month, they practiced $\mathrm{CW}$. All the variables were held constant during the two writing conditions and between the first and the second month. That is, the students did an equal amount of work for the first month as for the second. After the completion of the IW assignment, they completed the survey assessing their individual work. They filled out the questionnaire two times: first, when they finished the first month's assignments (presurvey), and second, when they completed the CW assignments at the end of the second month. This questionnaire (6-point Likert-type) was designed to measure students' views on and perceptions of CW and IW. Table 1 shows the course design and how the individual and CW conditions were divided. 
Table 1. The schedule of the writing course and the division of the writing assignments

\begin{tabular}{lll}
\hline Week & $\begin{array}{l}\text { First Month } \\
\text { (Individual Writing) }\end{array}$ & $\begin{array}{l}\text { Second Month } \\
\text { (Collaborative Writing) }\end{array}$ \\
\hline First week & Compare and contrast essay & Cause and effect essay \\
Second week & Writing process continues & Writing process continues \\
Third week & Descriptive essay & Narrative essay \\
Fourth week & Writing process continues & Writing process continues \\
& $\bullet \quad$ Presurvey administered & - Postsurvey administered \\
& & - CW opinion survey administered \\
& & - Interviews \\
\hline
\end{tabular}

\subsection{The Writing Course}

The main goal of the course was to teach students to write a three-paragraph essay. The course lasted for 2 months ( 8 weeks) and students met twice a week ( 3 hours each). For the first month (4 weeks), students wrote individually, whereas for the second month, they wrote collaboratively. The students were introduced to four types of essays during the course, out of which two types were designed for IW and two for CW. The four types of essays are as follows: (1) compare and contrast, (2) descriptive, (3) cause and effect, and (4) narrative. These types of essays were chosen because they are the most likely types of essays that students would write during their course of studies. Two types of essays (i.e., compare and contrast, descriptive) were selected for IW, and cause and effect and narrative were assigned for CW. The course instructor had been guiding the students to follow a particular process while writing their essays. The students spent 2 weeks on each type of essay.

\subsection{The Writing Tasks}

Four writing prompts were prepared for the writing assignments: two prompts for IW and two for CW. These prompts were different and based on the essay type. For instance, for the cause and effect essay, the students were given the question "Do you agree or disagree that using the phone while driving causes accidents? Use specific reasons and examples to support your opinion," and for compare and contrast, the students were given the question "Do you agree or disagree that there is a difference between watching a movie at the cinema and watching the movie at home? Use specific reasons and examples to support your opinion." These questions were purposely one level above the students' current proficiency level of English so that the students felt challenged and would learn while writing about the topic. Also, for CW, these topics allowed the students to brainstorm and discuss together as they shared ideas and experiences. Table 2 shows the schedule of writing each type of essay and the writing process that the students followed.

Table 2. The writing process schedule that students followed in writing each type of essay

\begin{tabular}{|c|c|c|c|}
\hline Day & Hour & Week 1 & Week 2 \\
\hline \multirow[t]{5}{*}{ Monday } & First hour & Introducing the lesson (type of essay) & Drafting/writing \\
\hline & Second hour & Prewriting process: & Revising, editing, and proofreading \\
\hline & & - $\quad$ Brainstorming & Turn in their first draft for grading \\
\hline & & - $\quad$ Mind-mapping & \\
\hline & Third hour & Planning and outlining the first draft & \\
\hline \multirow[t]{4}{*}{ Thursday } & & Search using resources: & Teachers' feedback: \\
\hline & All hours & - Library & - General revision \\
\hline & & - $\quad$ Computers in lab & - $\quad$ Students work on teacher's feedback \\
\hline & & & - Exercise to foster the lesson \\
\hline
\end{tabular}

\subsection{Data Collection and Analysis}

\subsubsection{Self-Report Scale}

Previous literature on EFL learners' perceptions on $\mathrm{CW}$ tasks reveals that $\mathrm{CW}$ activities offer language learners two opportunities: CW helps them improve writing skills as well as the four language skills (Shehadeh, 2011; Storch, 2005, 2011, 2013). Therefore, a Likert-type scale was designed to gather students' responses regarding the contribution of $\mathrm{CW}$ to their writing skills as well as their overall English language skills. This scale was used as a pre- and post-survey to track respondents' perceptions across time. Statistical Package for Social Sciences (SPSS, v. 23) was used to conduct statistical analyses. 
The questionnaire consisted of 12 items to gauge respondents' views regarding the two writing conditions they experienced. The survey was divided into two sections, each section having six items. The items in the first section were designed to ask students' views of how the assignments over the past month (i.e., either IW or CW) helped them improve their writing skills, whereas the six items in the second section focused on how the assignments contributed to their language learning improvement in general. For instance, items about writing skills included "I learned a lot from completing the assignments over the past month," and items about English language learning included "The assignments I received over the past month improved my overall English language skills." In responding to the questions, each item required students to choose one of the following options: (1) strongly disagree, (2) disagree, (3) neutral, (4) agree, (5) strongly agree, and (6) not applicable (see Appendix A). Through comparisons I sought to find out whether the participants changed their views after they had experienced CW compared to their views after experiencing IW assignments. The reliability of the survey was determined by assessing internal consistency using Cronbach's alpha. For the IW survey (i.e., presurvey), the six questions measuring writing skill had an alpha of .62, whereas the six questions measuring overall language skills had an alpha of .73. For the $\mathrm{CW}$ survey (i.e., post-survey), the six questions measuring writing skill had an alpha of .80 , whereas the six questions measuring overall language skills had an alpha of .39. The low Cronbach's alpha may be partly due to the fact that only six items constitute each subscale.

To gauge students' responses about their $\mathrm{CW}$ experience exclusively, a third questionnaire was designed and used in this study as a postsurvey only (see Appendix B). This survey consisted of 13 items to measure students' opinions regarding the $\mathrm{CW}$ process. The purpose of the questionnaire was to gain a sense of student perceptions of the CW process. The survey assessed students' attitudes toward the CW process, asking whether they: (1) had expressed their views in the group, (2) felt that the group got along well, and (3) found their collaborative process helpful overall. The questionnaire had specific questions about $\mathrm{CW}$ such as "People in my group listened to each other's ideas" and "one person in the group tended to be the leader." Each item of the survey allowed participants to choose one of the following five options: (1) strongly disagree, (2) disagree, (3) neutral, (4) agree, and (5) strongly agree.

Before the presurvey was administered, the students were assigned numbers from 1 to 30 . Only the instructor and the researcher had access to students' assigned numbers. Numbering the participants allowed the researcher to link their responses across time and keep track of their responses in both the pre- and post-surveys. Students were told to use their assigned number, and not their names, when completing all study material to ensure confidentiality.

\section{Results}

\subsection{Research Question 1: Ratings of Individual Writing Assignments}

A dependent-samples $t$-test was conducted to determine whether students' ratings of CW differ significantly from ratings of IW with regard to writing skills. The analyses revealed a statistically significant difference: ratings of $\mathrm{CW}(M=3.54, S D=0.82)$ were higher than ratings of IW $(M=2.72, S D=0.67)$, indicating that $\mathrm{CW}$ was rated as leading to higher writing skills, $t(29)=3.17, p=.004, \eta^{2}=.26$ (see Figure 1). The effect size indicates that $26 \%$ of the variance in writing skill ratings can be attributed to differences between CW and IW assignments, a large effect size by conventional standards (Cohen, 1988).

\subsection{Research Question 2: Ratings of Collaborative Writing Assignments}

Similar to the analysis above, a dependent-samples $t$-test was conducted to determine whether ratings of CW differ significantly from IW ratings with regard to overall English language skills. The analyses revealed a statistically significant difference: $\mathrm{CW}$ ratings $(M=3.61, S D=0.51)$ were higher than IW ratings $(M=2.89$, $S D=0.68)$, indicating that $\mathrm{CW}$ was associated with higher English language skills, $t(29)=3.99, p<.001, \eta^{2}$ $=.35$ (see Figure 1). The analysis indicates that $35 \%$ of the variance in English language skill ratings is attributable to differences between the two assignment types, a large effect size by conventional standards (Cohen, 1988). 


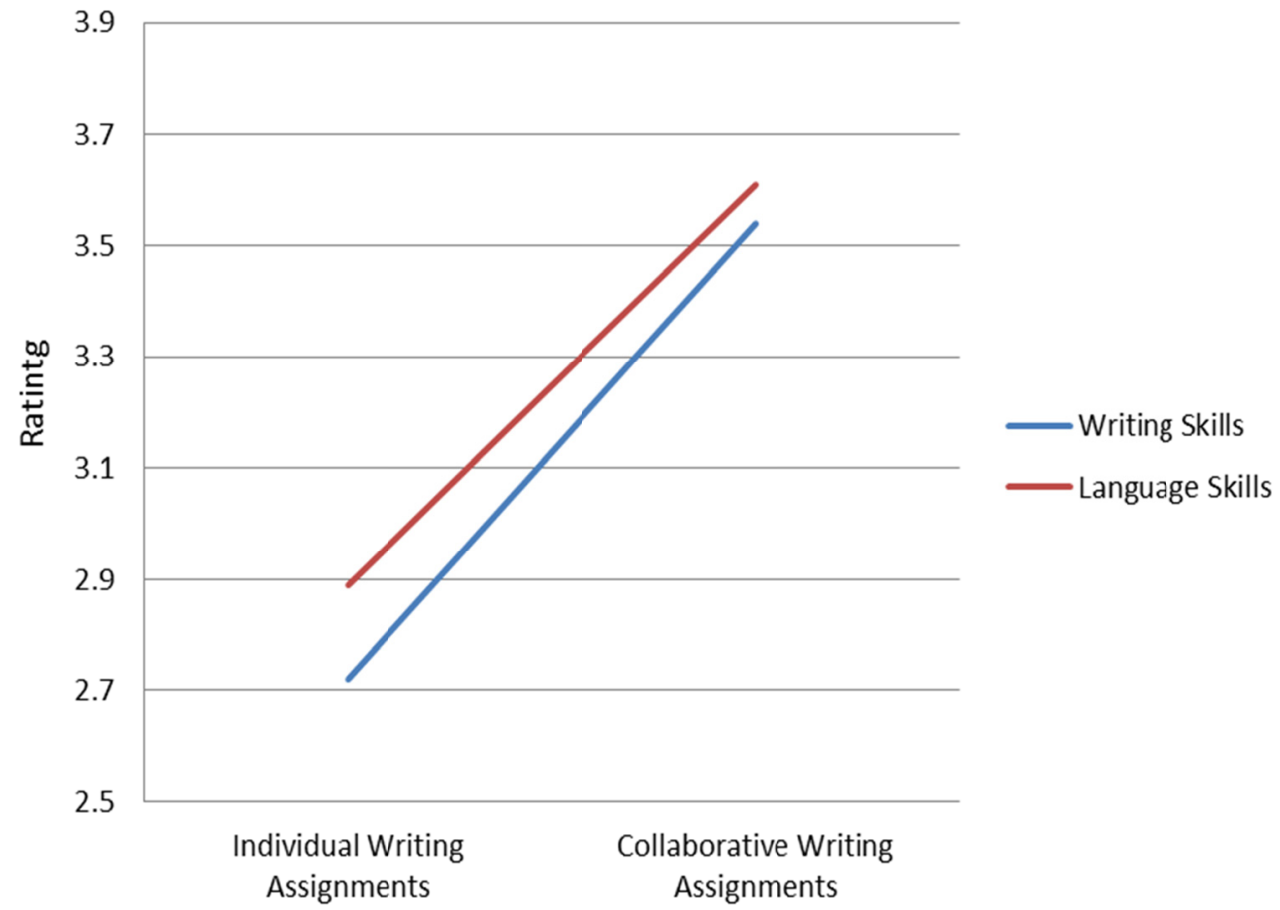

Figure 1. Ratings of writing and language skills improvement after IW and CW

\subsection{Research Question 3: Students' Perceptions of Collaborative Writing}

A 13-item Likert-type survey was administered after the last CW assignment to assess participants' general perceptions of the $\mathrm{CW}$ assignments. Table 3 shows the means, standard deviations, response frequencies, and response percentages. For data analysis, to determine the percentage of positive and negative responses of each item, the option strongly disagree was combined with disagree, and the option strongly agree was combined with agree.

Table 3. Response frequencies and descriptive statistics for collaborative writing opinion survey

\begin{tabular}{lllllllll}
\hline Item & Strongly Disagree (\%) & Disagree (\%) & Neutral (\%) & Agree (\%) & Strongly Agree (\%) & N/A (\%) & $M$ & $S D$ \\
\hline 1. & $4(13)$ & $4(13)$ & $5(17)$ & $9(30)$ & $8(27)$ & $0(0)$ & 3.43 & 1.38 \\
2. & $2(7)$ & $5(17)$ & $6(20)$ & $7(23)$ & $9(30)$ & $1(3)$ & 3.63 & 1.35 \\
3. & $4(13)$ & $8(27)$ & $3(10)$ & $11(37)$ & $3(10)$ & $1(3)$ & 3.13 & 1.38 \\
4. & $0(0)$ & $3(10)$ & $8(27)$ & $8(27)$ & $10(33)$ & $1(3)$ & 3.93 & 1.08 \\
5. & $2(7)$ & $3(10)$ & $6(20)$ & $6(20)$ & $13(43)$ & $0(0)$ & 3.83 & 1.29 \\
6. & $1(3)$ & $3(10)$ & $2(7)$ & $9(30)$ & $13(43)$ & $2(7)$ & 4.20 & 1.22 \\
7. & $0(0)$ & $2(7)$ & $6(20)$ & $8(27)$ & $13(43)$ & $1(3)$ & 4.17 & 1.02 \\
8. & $1(3)$ & $3(10)$ & $5(17)$ & $7(23)$ & $13(43)$ & $1(3)$ & 4.03 & 1.22 \\
9. & $0(0)$ & $2(7)$ & $4(13)$ & $5(17)$ & $18(60)$ & $1(3)$ & 4.40 & 1.00 \\
10. & $0(0)$ & $3(10)$ & $7(23)$ & $7(23)$ & $10(33)$ & $3(10)$ & 4.10 & 1.19 \\
11. & $8(27)$ & $11(37)$ & $5(17)$ & $1(3)$ & $1(3)$ & $4(13)$ & 2.60 & 1.65 \\
12. & $0(0)$ & $1(3)$ & $5(17)$ & $12(40)$ & $10(33)$ & $2(7)$ & 4.23 & 0.94 \\
13. & $0(0)$ & $1(3)$ & $3(10)$ & $8(27)$ & $17(57)$ & $1(3)$ & 4.47 & 0.86 \\
Total & $22(6)$ & $49(13)$ & $65(18)$ & $97(26)$ & $138(37)$ & $18(5)$ & 3.86 & 0.43 \\
\hline
\end{tabular}

Item 1 in the survey was "I got the chance to express my views in the group." Of the total $(N=30), 13 \%(n=4)$ strongly disagreed, $13 \%(n=4)$ disagreed, $30 \%(n=9)$ agreed, and $27 \%(n=8)$ strongly agreed. Seventeen percent $(n=4)$ of the participants were neutral. Taken as a whole, the level of agreement among participants (i.e., $57 \%$ ) indicates a higher level of positive attitudes toward CW compared to the level of disagreement (i.e., 26\%). A higher level of agreement indicates that group work offered more chances for students to share their views with peers. 
Item 2 in the survey was "I prefer doing collaborative writing than writing individually." Of the total $(N=30), 7 \%$ $(n=2)$ strongly disagreed, $17 \%(n=5)$ disagreed, 23\% $(n=7)$ agreed, and 30\% $(n=9)$ strongly agreed. Twenty percent $(n=6)$ of the participants were neutral while $3 \%(n=1)$ responded not applicable. Taken as a whole, the level of agreement among participants (i.e., 53\%) indicates a higher level of positive attitudes toward CW compared to the level of disagreement (i.e., 24\%). A higher tendency in responses toward agreement indicates that students preferred CW to IW.

Item 3 in the survey was "My ideas got into the papers we wrote." Of the total $(N=30), 13 \%(n=4)$ strongly disagreed, 27\% $(n=8)$ disagreed, 37\% $(n=11)$ agreed, and 10\% $(n=3)$ strongly agreed. Ten percent $(n=3)$ of the participants were neutral, while $3 \%(n=1)$ selected not applicable. Taken as a whole, the level of agreement among participants (i.e., $47 \%$ ) indicates a slightly higher level of positive attitudes toward $\mathrm{CW}$ compared to the level of disagreement (i.e., $40 \%$ ). Students' responses show positive attitudes toward the incorporation of their ideas in papers, slightly higher than students who reported negative attitudes toward $\mathrm{CW}$ when it came to the incorporation of their ideas into papers.

Item 4 in the survey was "I got along with everybody in the group." Of the total $(N=30), 0 \%(n=0)$ strongly disagreed, 10\% $(n=3)$ disagreed, 27\% $(n=8)$ agreed, and 33\% $(n=10)$ strongly agreed. Twenty-seven percent $(n=8)$ of the participants were neutral while 3\% $(n=1)$ selected not applicable. Taken as a whole, the level of agreement among participants (i.e., $60 \%$ ) indicates a very high level of positive attitudes toward $\mathrm{CW}$ compared to the level of disagreement (i.e., 10\%). Such a higher tendency toward CW in students' responses indicates that $\mathrm{CW}$ encouraged group coherence among students, which is one of the defining characteristics of $\mathrm{CW}$.

Item 5 in the survey was "People in my group listened to each other's ideas." Of the total $(N=30), 7 \%(n=2)$ strongly disagreed, $10 \%(n=3)$ disagreed, $30 \%(n=6)$ agreed, and $43 \%(n=13)$ strongly agreed. Twenty percent $(n=6)$ of the participants were neutral while none of them selected not applicable. Taken as a whole, the level of agreement among participants (i.e., 63\%) indicates a higher level of positive attitudes toward $\mathrm{CW}$ compared to the level of disagreement (i.e., 17\%). Such a higher tendency toward CW in students' responses indicates that $\mathrm{CW}$ encouraged students to listen to one another's ideas and incorporate them accordingly for the benefit of the writing process.

Item 6 in the survey was "Writing together we spent more time revising papers than I do when I write alone." Of the total $(N=30), 3 \%(n=1)$ strongly disagreed, $10 \%(n=3)$ disagreed, $30 \%(n=9)$ agreed, and $43 \%(n=13)$ strongly agreed. Seven percent $(n=2)$ of the participants were neutral, while $7 \%(n=2)$ selected not applicable. Taken as a whole, the level of agreement among participants (i.e., 73\%) indicates a very high level of positive attitudes toward $\mathrm{CW}$ compared to the level of disagreement (i.e., 13\%). A very high level of tendency toward $\mathrm{CW}$ in students' responses indicates the effectiveness of $\mathrm{CW}$ in terms of time saving.

Item 7 in the survey was "Writing together we spent more time checking spelling, punctuation, and grammar than I do when I write alone." Of the total $(N=30), 0 \%(n=0)$ strongly disagreed, $7 \%(n=2)$ disagreed, $27 \%(n$ $=8)$ agreed, and $43 \%(n=13)$ strongly agreed. Twenty percent $(n=6)$ of the participants were neutral, while $3 \%$ $(n=1)$ selected not applicable. Taken as a whole, the level of agreement among participants (i.e., $70 \%)$ indicates a very high level of positive attitudes toward $\mathrm{CW}$ compared to the level of disagreement (i.e., 7\%). The highest level of agreement in students' responses tends to show that $\mathrm{CW}$ effectively offers students the opportunity to save time on revisions and error corrections as compared to IW.

Item 8 in the survey was "Every member of the group put about the same amount of effort into writing the papers." Of the total $(N=30), 3 \%(n=1)$ strongly disagreed, $10 \%(n=3)$ disagreed, $23 \%(n=7)$ agreed, and $43 \%$ $(n=13)$ strongly agreed. Seventeen percent $(n=5)$ of the participants were neutral, while $3 \%(n=1)$ selected not applicable. Taken as a whole, the level of agreement among participants (i.e., 70\%) indicates a higher level of positive attitudes toward CW compared to the level of disagreement (i.e., 13\%). The highest level of agreement in students' responses indicates that $\mathrm{CW}$ encouraged group collaboration, and students' individual efforts in terms of input effectively contributed to the final product.

Item 9 in the survey was "We wrote all parts of the paper together rather than dividing up the work." Of the total $(N=30), 0 \%(n=0)$ strongly disagreed, $7 \%(n=2)$ disagreed, 17\% $(n=5)$ agreed, and 60\% $(n=18)$ strongly agreed. Thirteen percent $(n=4)$ of the participants were neutral, while $3 \%(n=1)$ selected not applicable. Taken as a whole, the level of agreement among participants (i.e., 77\%) indicates a higher level of positive attitudes toward CW compared to the level of disagreement (i.e., 7\%). The highest level of agreement in students' responses indicates that $\mathrm{CW}$ encouraged group collaboration and a cohesive product.

Item 10 in the survey was "Members of my group sometimes disagree about what to say or how to say it." Of the total $(N=30), 0 \%(n=0)$ strongly disagreed, $10 \%(n=3)$ disagreed, $23 \%(n=7)$ agreed, and $33 \%(n=10)$ 
strongly agreed. Twenty-three percent $(n=7)$ of the participants were neutral, while $10 \%(n=3)$ selected not applicable. Taken as a whole, the level of agreement among participants (i.e., 56\%) indicates a higher level of positive attitudes toward $\mathrm{CW}$ compared to the level of disagreement (i.e., 10\%). The highest level of agreement in students' responses indicates that $\mathrm{CW}$ allowed students to disagree on some points which, in turn, encouraged the incorporation of the most relevant ideas into the product.

Item 11 in the survey was "One person in the group tended to be the leader." Of the total $(N=30), 27 \%(n=8)$ strongly disagreed, $11 \%(n=37)$ disagreed, $3 \%(n=1)$ agreed, and $3 \%(n=1)$ strongly agreed. Fifteen percent $(n=5)$ of the participants were neutral, while $13 \%(n=4)$ selected not applicable. Taken as a whole, the level of disagreement among participants (i.e., 57\%) indicates a higher level of positive attitudes toward CW compared to the level of disagreement (i.e., 26\%). The highest level of disagreement in students' responses indicates that $\mathrm{CW}$ encouraged students to disagree on some points which, in turn, encouraged group work and inclusion of every team member as a core part of the team and discouraged an individual student's dominance.

Item 12 in the survey was "I would like to write collaboratively again." Of the total $(N=30), 0 \%(n=0)$ strongly disagreed, 3\% $(n=1)$ disagreed, $40 \%(n=12)$ agreed, and 33\% $(n=10)$ strongly agreed. Seventeen percent $(n=$ $5)$ of the participants were neutral, while $7 \%(n=2)$ selected not applicable. Taken as a whole, the level of agreement among participants (i.e., 73\%) indicates a very high level of positive attitudes toward CW compared to the level of disagreement (i.e., 3\%). The highest level of agreement in students' responses shows the tendency toward encouragement of $\mathrm{CW}$ and discouragement of IW.

Item 13 in the survey was "I learned more from collaborative writing assignments than individual writing assignments." Of the total $(N=30), 0 \%(n=0)$ strongly disagreed, $3 \%(n=1)$ disagreed, $27 \%(n=8)$ agreed, and $57 \%(n=17)$ strongly agreed. Three percent $(n=1)$ of the participants were neutral, while $3 \%(n=1)$ selected not applicable. Taken as a whole, the level of agreement among participants (i.e., 84\%) indicates a higher level of positive attitudes toward CW compared to the level of disagreement (i.e., 3\%). The highest level of agreement in students' responses indicates that $\mathrm{CW}$ was highly productive in terms of learning as compared to IW.

To conclude, it is noteworthy that the mean across all 13 items is $3.86(S D=0.43)$, indicating that participants as a group have positive perceptions of $\mathrm{CW}$ (i.e., given that an answer of 4 on every item indicates agree). Similarly, the most frequently provided answer across all scale items was strongly agree, amounting to 138 of the $371(37 \%)$ responses. Lastly, the highest rated item was Item 13, "I learned more from collaborative writing assignments than individual writing assignments" $(M=4.47, S D=0.86)$, providing further evidence that students felt the $\mathrm{CW}$ assignments were more worthwhile and educational than the more traditional IW assignments. The lowest rated item, on the other hand, was Item 11, "One person in the group tended to be the leader" $(M=4.47, S D=0.86)$, suggesting that the $\mathrm{CW}$ assignments were indeed collaborative and all group members contributed and participated in the assignments (see Table 3).

\section{Results and Discussion}

This study aimed to explore participants' attitudes toward CW as compared to their views toward IW. A self-report survey (6-point Likert scale) was used to investigate learners' perceptions of CW (see Appendices A and B). Also, semi-structured interviews were conducted to gain qualitative insights while exploring the participants' views toward the two writing conditions they experienced as well as to find out the benefits and challenges they faced. Four research questions guided the study, and the results are listed and explained as follows.

Question 1: What are the students' ratings of IW assignments with regard to improving their writing skills? And what are their ratings of $I W$ assignments with regard to improving their English language skills? A questionnaire (Likert-type) was used to answer the above research question. The questionnaire items were designed to ask students' views of how the IW assignments helped them improve their writing skills, specifically, and their overall English language skills, in general. The questionnaire was divided into two sections, with six items in each section. The items in the first section were designed to ask students' views of how the IW assignments helped them improve their writing skills, whereas the six items in the second section focused on how these assignments contributed to their language learning improvement in general (see Appendix A).

The findings revealed that students rated IW assignments low with regard to improving their writing skills as well as improving their English language skills in general. This low rating of individual assignments indicates that they did not prefer writing individually because it does not boost their language learning in general or their writing skills in particular. As shown in Figure 1, students' ratings of IW assignments with regard to writing skills were $(M=2.72, S D=0.67)$, and their ratings with regard to their language learning improvement in 
general were $(M=2.90, S D=0.89)$ (see Figure 1). This low rating of IW assignments indicates that these assignments were not effective in helping students improve their writing skills or their overall language learning. In other words, students did not find the IW assignments to be a useful method to develop their writing skills or their language learning in general.

Question 2: What are the students' ratings of $C W$ assignments with regard to improving their writing skills? And what are their ratings of $\mathrm{CW}$ assignments with regard to improving their English language skills? Similar to Question 1, that is, to determine whether students' ratings of CW assignments differ significantly from their ratings of IW assignments, the same scale was used. The questionnaire items were designed to ask students' views of how the $\mathrm{CW}$ assignments helped them improve their writing skills and their English language skills. The first six items were designed to ask students' views of how the CW assignments helped them improve their writing skills, whereas the other six items focused on how these assignments contributed to their language learning improvement in general (see Appendix A).

The findings revealed that students' ratings of $\mathrm{CW}$ assignments were high with regard to improving their writing skills as well as their English language skills in general. This high rating of $\mathrm{CW}$ assignments indicates that they favored writing collaboratively because they found it helpful to support their language learning as well as their writing skills. As shown in Figure 1, students' ratings of CW assignments with regard to writing skills were ( $M=$ $3.54, S D=0.82)$, and their ratings with regard to their language learning improvement were $(M=3.61, S D=$ 0.51 ) (see Figure 1). These high ratings of $\mathrm{CW}$ assignments indicate that these assignments were effective in helping students improve their writing skills as well as their overall language learning. Unlike students' ratings of IW assignments, their ratings of $\mathrm{CW}$ assignments were high, which indicates that they found $\mathrm{CW}$ more helpful and that it contributed not only to improvement of their writing skills but also of their language learning in general. In other words, students' ratings of $\mathrm{CW}$ showed that they found $\mathrm{CW}$ a useful method in developing not only their writing skills but also their language learning in general. This means that the majority of the students favored writing collaboratively over IW because they found it useful to improve their writing skills as well as their learning of English language skills.

Question 3: After having the opportunity to engage in CW assignments, what are students' attitudes toward CW? To gauge students' responses about their $\mathrm{CW}$ experience exclusively, a questionnaire was used in this study to answer the third research question (see Appendix B). This survey consisted of 13 items to measure students' opinions regarding the $\mathrm{CW}$ process. The purpose of the questionnaire was to gain a sense of student perceptions of the CW process. The survey assessed students' attitudes toward the CW process, asking whether they: (1) had expressed their views in the group, (2) felt that the group got along well, and (3) found the collaborative process helpful overall. The questionnaire had specific questions about CW such as "People in my group listened to each other's ideas and one person in the group tended to be the leader." Each item of the survey allowed participants to choose one of the following five options: (1) strongly disagree, (2) disagree, (3) neutral, (4) agree, and (5) strongly agree. Descriptive statistics were applied to assess the respondents' scores and present the findings (i.e., means, standard deviations, frequencies, and response percentages).

The analysis of the questionnaire revealed that the mean across all 13 survey items was $3.86(S D=0.43)$, indicating that participants as a group have positive perceptions of CW (i.e., given that an answer of 4 on every item indicates agree). Similarly, the most frequently provided answer across all scale items was strongly agree, amounting to 138 of the 371 (37\%) responses. Lastly, the highest rated item was Item 13, "I learned more from collaborative writing assignments than individual writing assignments" $(M=4.47, S D=0.86)$, providing further evidence that students found $\mathrm{CW}$ assignments more worthwhile and educational than the more traditional IW assignments. The lowest rated item, on the other hand, was Item 11, "One person in the group tended to be the leader" ( $M=4.47, S D=0.86)$, suggesting that the $\mathrm{CW}$ assignments were indeed collaborative and all group members contributed and participated in the assignments (see Table 3).

The above findings based on the questionnaire data revealed that the majority of the participants expressed positive attitudes toward the incorporation of their ideas in papers. Also, a statistically significant number of participants not only liked writing with their partners more than writing alone, but also thought that they wrote better papers with their partners than alone. Moreover, a statistically significant number of participants liked the writing processes of planning, writing, and editing/revising when they did them with their partners rather than doing them alone. This indicates that they preferred CW to the IW assignments. The respondents' positive attitudes on the questionnaire toward the $\mathrm{CW}$ process showed that they found $\mathrm{CW}$ helpful for their writing, particularly for idea generation, essay organization, grammar, and vocabulary.

Question 4: Judging from students' perceptions, what are the perceived benefits and challenges of CW for EFL 
learners? What difficulties do they experience when engaging in CW? Semi-structured interviews were conducted to gain qualitative insights while exploring the participants' point of view toward the two writing conditions they experienced as well as to find out the benefits and challenges they faced. This research paradigm was expected to yield new insights into what EFL learners think of individual and collaborative writing and how these two different writing assignments help them with their language learning in general and writing skills in particular.

After students completed the course, I randomly selected 10 students (1 participant from each group) out of the total sample for a semi-structured interview aiming to gauge students' opinions about their experience with the two writing conditions. The interview was conducted in English and lasted for 20 to 30 minutes with each participant. I audiorecorded and transcribed the interviews verbatim. The participants were asked questions such as: (a) how they felt about each writing condition, (b) whether the condition hindered or assisted them in the writing process, and (c) how they felt about each assignment. Participants were also specifically asked how they found IW different from $\mathrm{CW}$, which writing condition they found more useful and enjoyable, and which condition contributed more to their language learning.

The interviews with the participants were conducted immediately after the class and yielded some noteworthy insights about their reaction to $\mathrm{CW}$. The majority of the participants responded that they were able to improve their writing and speaking skills to some extent. They were able to benefit from the $\mathrm{CW}$ experience as they gained new ideas and vocabulary, and learned a number of learning innovations and revision strategies. In addition, they developed a broader perspective of thinking in regard to language learning. Many of them affirmed that they learned how to produce more complex sentence structures and how to follow the rhetorical aspects of academic essays more systematically. For instance, Student 6 affirmed:

My problem when I write I don't know how to connect the sentences together because paragraph is not good but when I write with my friends we write good essay together, they bring sentences, and we connects them together. They always said to me I must connect the sentences together.

In a similar vein, Student 17 stated:

Sometimes I ask the teacher about how write good sentences and he doesn't answer very well. He answers, but in quickly and different way. When I work with my group with my classmates, and I ask them questions about how to start to write first line and until last line in essay. They always answer, and how we do that together.

Furthermore, their confidence in writing grew and many of them felt less apprehensive about writing on their own. As Student 7 mentioned:

I always worried about writing when I have homework because I think my writing is very bad, but now I am happy because my writing is like my friends. We write the same way and we learn from each other when we writing together.

They also developed a sense of audience and tried to write clearly. For instance, Student 9 affirmed:

I feel I learn from my friends now more about grammar and new words in English more than before. Sometimes, while we write I give them one word and they say, "No, no. We should use another word much better." I like their ideas. They always bring good words, and we use them in our writing. Also, I will use what I learn from my friends when I write my homework next time.

In fact, they intended to apply the knowledge they gained during the collaboration into their own individual writing.

On the whole, the participants did not report serious complications while working within their groups. The majority of them liked working in groups because they were exposed to new ideas and learned new ways of writing. For example, Student 1 affirmed, "If writing alone, I stick to one point. But with my group, we can share points and ideas, and discuss, and we can produce better writing. I like to write with my friends in my group." Similarly, Student 2 said, "Writing in the group is better than writing alone because in group writing help to bring more ideas and then we will have good writing essay." They also seemed to be delighted working with peers whom they were familiar with. Their dislike of group work was due to a sense of inadequacy, working with unknown partners. For instance, Student 7 stated, "Sometimes, my group have some problems because we don't know each other before [and] not close friends. It's our first time to be in one group, we don't want to hurt each other." Time constraints were also highlighted as one of the problems in CW as Student 8 pointed out:

...the problem I have, I think, we need more time. The teacher did not give enough time for writing. We 
take more time in first draft. We brainstorm, plan and it's very difficult to do many things in short time.

It is quite evident that the participants found it easy to participate in groups despite the disagreements and differences in opinions. The weaker students obtained assistance and help from stronger members as Student 8 stated, "I think I have two friends in my group, who are weak in writing. I always teach them when we write the essay, and I think they improved their writing at the end." Similarly, Student 2 affirmed, "I learn new ways in writing every essay because I see how my friends write. My friends tell me how to introduce the topic and summarize the essay, and also how much I should write in the main body." At the same time, the participants felt that they expanded their writing repertoire by observing how other members explored and tested their ideas. By the time the second task began, students' collaboration had already been improved.

\section{Discussion}

Based on the survey findings and interview responses, it is evident that the majority of respondents had a positive perception of the use of $\mathrm{CW}$ in the classroom in terms of a variety of aspects. For example, in terms of motivation, students felt that $\mathrm{CW}$ improved their confidence to write in English. This finding aligned with Shehadeh (2011), whose subjects found CW helpful in enhancing their self-confidence, and Yang, Badger and $\mathrm{Yu}$ (2006), who proposed that collaboration fosters camaraderie and self-confidence. Two sociocultural constructs commonly identified in $\mathrm{CW}$, the co-construction of knowledge and languaging, were also cited by students as major benefits. Most of the respondents agreed that the group discussed the best way to use the target language to express their ideas in terms of grammar, vocabulary, sentence structure, and spelling. This corresponds to instances of languaging or language-related episodes identified in Swain (2006) and used as a variable in a number of studies (e.g., Dobao, 2012; Jafari \& Ansari, 2012; Shehadeh, 2011; Storch, 2005, 2009) on CW. It was shown, for instance, that frequencies of language-related episodes corresponded to quality of written text produced (Watanabe \& Swain, 2007).

The results of the present study confirm Storch's (2005) findings that most of the students who participated in her study (16 of 18) were generally positive regarding the CW experience. Almost all the participants in the present study were also positive about the activity, enjoyed the experience, and stated that it was a source of learning for them, although two students stated that they would prefer to be given the choice to select their partners (Shehadeh, 2011).

Furthermore, the interview responses suggest that the respondents perceived $\mathrm{CW}$ to have had a positive impact on their grammar. This is in line with numerous past studies (e.g., Storch, 1999, 2005; Storch \& Wigglesworth, 2007), which found that collaboration had a positive effect on overall grammatical accuracy. Storch (2005) and Chao and Lo's (2011) studies also revealed that students perceived greater grammatical accuracy to be one of the benefits of collaboration. In addition to that, the participants who showed a preference for writing in groups felt that there were more ideas to share and more opportunities to provide and receive assistance from peers. Their perceptions reflect the findings of previous research, which indicates the $\mathrm{CW}$ tasks, both in pairs and in small groups, offer learners the opportunity to pool their individual ideas and knowledge (e.g., Dobao, 2012; Jafari \& Ansari, 2012; Kim, 2008; Storch, 2005; Storch \& Wigglesworth, 2007; Swain \& Lapkin, 1998).

On the other hand, as observed in previous studies, such as Storch (2005) and Shehadeh (2011), the number of students who expressed a preference for individual over collaborative writing was extremely limited, that is, only 4 out of 55. In previous research, the most commonly cited argument in favor of IW is the idea that writing is an inherently individual task (Elola \& Oskoz, 2010; Storch, 2005). Learners have also been found to prefer individual work when they lack confidence in their own language skills or feel uncomfortable correcting or criticizing their peers (Storch, 2005). Perhaps these were major concerns for the present study's participants because of the nature of the task, which was oriented to develop not only learners' writing skills, but also their vocabulary and grammar knowledge. The only two learners who stated a preference for IW raised issues of them being less confident in their English or afraid of offending their partners, such as "I like to work alone because I think my friends don't understand my English" or "I want to write alone because sometimes I feel my friends get angry when I correct their English or writing." Taking these points into consideration, learners who lack self-confidence in English proficiency or fear offending others would be impeded from working in their ZPD.

It is also necessary to point out that the majority of the participants felt that $\mathrm{CW}$ assignments helped them develop their lexical and grammatical knowledge, because, as Student 8 stated, "again, we use English in discussion." These learners saw the positive impact of CW not only on their writing abilities, but also on their learning of the English language in general. This may happen due to their use of the target language, which improved their fluency and overall speaking skills as well. These findings are in line with other studies (e.g., Dobao \& Blum, 2013; Jafari \& Ansari, 2012; Shehadeh, 2011; Storch, 2005, 2009) that found that their 
participants expressed a preference for CW to IW assignments due to the opportunities that CW offered not only to learn from each other about writing, but also to practice their English with peers without being afraid of making mistakes.

Finally, obtaining insights from students who have used the collaborative approach is important for curriculum designers, textbook planners, and EFL writing instructors to implement writing tasks for students to collaborate on. The findings of the present study showed that the $\mathrm{CW}$ approach is a preferable teaching method from the perspective of learners. Therefore, the main pedagogical implication that arises from the present findings is that L2 teachers, particularly EFL writing instructors, could benefit from using CW tasks to enhance their students' writing as well as offer them an opportunity to learn from one another. The present study demonstrated that $\mathrm{CW}$ assignments have a place in EFL writing classrooms.

\section{Acknowledgment}

The author would like to thank Deanship of Scientific Research at Majmaah University for supporting this work under Project Number: R-1441-76.

\section{References}

AlKhairy, M. A. (2013). Saudi English-major undergraduates' academic writing problems: A Taif University perspective. English Language Teaching, 6(6), 1. https://doi.org/10.5539/elt.v6n6p1

Ansari, A. A. (2012). Teaching of English to Arab students: Problems and remedies. Educational Research, 3(6), 519-524.

Biria, R., \& Jafari, S. (2013). The impact of collaborative writing on the writing fluency of Iranian EFL learners. Journal of Language Teaching and Research, 4(1), 164-175. https://doi.org/10.4304/jltr.4.1.164-175

Bruffee, K. A. (1973). Collaborative learning: Some practical models. College English, 34(5), 634-643. https://doi.org/10.2307/375331

Chao, Y., \& Lo, H. (2011). Students' perceptions of wiki-based collaborative writing for learners of English as a foreign language. Interactive Learning Environments, 19(4), 354-411. https://doi.org/10.1080/10494820903298662

Cohen, J. (1988). Statistical power analysis: A computer program. Hillsdale, NJ: Routledge.

Dobao, A. F. (2012). Collaborative writing tasks in the L2 classroom: Comparing group, pair, and individual work. Journal of Second Language Writing, 21(1), 40-58. https://doi.org/10.1016/j.jslw.2011.12.002

Dobao, A. F., \& Blum, A. (2013). Collaborative writing in pairs and small groups: Learners' attitudes and perceptions. System, 41(2), 365-378. https://doi.org/10.1016/j.system.2013.02.002

Dörnyei, Z., \& Kormos, J. (2000). The role of individual and social variables in oral task performance. Language Teaching Research, 4(3), 275-300. https://doi.org/10.1177/136216880000400305

Elola, I., \& Oskoz, A. (2010). Collaborative writing: Fostering foreign language and writing conventions development. Language, Learning \& Technology, 14(3), 51-71.

Green, J. M. (1993). Student attitudes toward communicative and non - communicative activities: Do enjoyment and effectiveness go together? The Modern Language Journal, 77(1), 1-10. https://doi.org/10.1111/j.1540-4781.1993.tb01938.x

Hamp-Lyons, L. (1991). Scoring procedures for ESL contexts. In L. Hamp-Lyons (Ed.), Assessing second language writing in academic contexts (pp. 241-276). Norwood, NJ: Ablex.

Harste, J. C. (1984). Language stories \& literacy lessons. Portsmouth, NH: Heinemann Educational Books.

Horwitz, E. K. (1999). Cultural and situational influences on foreign language learners' beliefs about language learning: A review of BALLI studies. System, 27(4), 557-576. https://doi.org/10.1016/S0346-251X(99)00050-0

Huwari, I. F., \& Al-Khasawneh, F. M. (2013). The reasons behind the weaknesses of writing in English among pre-year students' at Taibah University. English for Specific Purposes World, 38(14), 1-9.

Jacobs, G. M. (2004, September). Cooperative learning: Theory, principles, and techniques. Paper presented at the First International Online Conference on Second and Foreign Language Teaching and Research.

Jafari, N., \& Ansari, D. N. (2012). The effect of collaboration on Iranian EFL learners' writing accuracy. International Education Studies, 5(2), 125-131. https://doi.org/10.5539/ies.v5n2p125 
Johns, A. M. (1991). Interpreting an English competency examination: The frustrations of an ESL science student. Written Communication, 8(3), 379-401. https://doi.org/10.1177/0741088391008003004

Kennedy, C., \& Kennedy, J. (1996). Teacher attitudes and change implementation. System, 24(3), 351-360. https://doi.org/10.1016/0346-251X(96)00027-9

Kim, Y. (2008). The contribution of collaborative and individual tasks to the acquisition of L2 vocabulary. Modern Language Journal, 92(1), 114-130. https://doi.org/10.1111/j.1540-4781.2008.00690.x

Kuiken, F., \& Vedder, I. (2002). The effect of interaction in acquiring the grammar of a second language. International Journal of Educational Research, 37(3), 343-358. https://doi.org/10.1016/S0883-0355(03)00009-0

Leki, I. (1995). Coping strategies of ESL students in writing tasks across the curriculum. TESOL Quarterly, 29(2), 235-260. https://doi.org/10.2307/3587624

Lin, O. P., \& Maarof, N. (2013). Collaborative writing in summary writing: Student perceptions and problems (Vol. 90, pp. 599-606). In Procedia - Social and Behavioral Sciences. $6^{\text {th }}$ International Conference on University Learning and Teaching (In CULT 2012). https://doi.org/10.1016/j.sbspro.2013.07.131

Littlewood, W. (2011). Communicative language teaching: An expanding concept for a changing world. In E. Hinkel (Ed.), Handbook of research in second language teaching and learning (Vol. II, pp. 541-557). London, England: Routledge.

Long, M. H., \& Porter, P. A. (1985). Group work, interlanguage talk, and second language acquisition. TESOL Quarterly, 19(2), 207-228. https://doi.org/10.2307/3586827

McDonough, K. (2004). Learner-learner interaction during pair and small group activities in a Thai EFL context. System, 32(2), 207-224. https://doi.org/10.1016/j.system.2004.01.003

Mishra, S., \& Oliver, R. (1998). Secondary school ESL learners' perceptions of pair work in Australian classrooms. TESOL in Context, 8(2), 19-23.

Nassaji, H., \& Tian, J. (2010). Collaborative and individual output tasks and their effects on learning English phrasal verbs. Language Teaching Research, 14(4), 397-419. https://doi.org/10.1177/1362168810375364

Nixon, R. M. (2007). Collaborative and independent writing among adult Thai EFL learners: Verbal interactions, compositions, and attitudes. Unpublished doctoral dissertation. University of Toronto, Canada.

Petric, B. (2002). Students' attitudes towards writing and the development of academic writing skills. Writing Center Journal, 22(2), 9-27.

Prior, P. (2006). A sociocultural theory of writing. In C. A. MacArthur, S. Graham \& J. Fitzgerald (Eds.), Handbook of writing research (pp. 54-66). New York, NY: Guilford.

Reinders, H. (2009). Learner uptake and acquisition in three grammar-oriented production activities. Language Teaching Research, 13(2), 201-222. https://doi.org/10.1177/1362168809103449

Riley, P. A. (2009). Shifts in beliefs about second language learning. RELC Journal, 40(1), 102-124. https://doi.org/10.1177/0033688208101448

Shehadeh, A. (2011). Effects and student perceptions of collaborative writing in L2. Journal of Second Language Writing, 20(4), 286-305. https://doi.org/10.1016/j.jslw.2011.05.010

Speck, B. W. (2002). Facilitating students' collaborative writing. ASHE-ERIC Higher Education Report, 28(6).

Stahl, G. (2006). Group cognition: Computer support for building collaborative knowledge (pp. 451-473). Cambridge, MA: MIT Press. https://doi.org/10.7551/mitpress/3372.001.0001

Storch, N. (1999). Are two heads better than one? Pair work and grammatical accuracy. System, 27(3), 363-374. https://doi.org/10.1016/S0346-251X(99)00031-7

Storch, N. (2005). Collaborative writing: Product, process, and students' reflections. Journal of Second Language Writing, 14, 153-173. https://doi.org/10.1016/j.jslw.2005.05.002

Storch, N. (2008). Metatalk in a pair work activity: Level of engagement and implications for language development. Language Awareness, 17(2), 95-114. https://doi.org/10.1080/09658410802146644

Storch, N. (2009). The nature of pair interaction. Learners' interaction in an ESL class: Its nature and impact on grammatical development. Saarbrücken, Germany: VDM Verlag.

Storch, N. (2011). Collaborative writing in L2 contexts: Processes, outcomes, and future directions. Annual 
Review of Applied Linguistics, 31, 275-288. https://doi.org/10.1017/S0267190511000079

Storch, N. (2013). Collaborative writing in L2 classrooms. Bristol, England: Multilingual Matters. https://doi.org/10.21832/9781847699954

Storch, N., \& Wigglesworth, G. (2007). Writing tasks: The effects of collaboration. In M. del Pilar García Mayo (Ed.), Investigating tasks in formal language learning (pp. 157-177). Clevedon, England: Multilingual Matters. https://doi.org/10.21832/9781853599286-011

Swain, M. (2006, April). Languaging, agency and collaboration in second language learning. Plenary address at BAAL Language Learning and Teaching SIG Conference: Language Use, Language Processing and Language Learning, University of Southampton, England.

Swain, M. (2010). 'Talking-it-through': Languaging as a source of learning. In R. Batstone (Ed.), Socio-cognitive perspectives on language use and language learning (pp. 112-130). Oxford, England: Oxford University Press.

Swain, M., Brooks, L., \& Tocalli-Beller, A. (2002). Peer-peer dialogue as a means of second language learning. Annual Review of Applied Linguistics, 22, 171-185. https://doi.org/10.1017/S0267190502000090

Swain, M., \& Lapkin, S. (1998). Interaction and second language learning: Two adolescent French immersion students working together. Modern Language Journal, 82(3), 320-337. https://doi.org/10.1111/j.1540-4781.1998.tb01209.x

Swain, M., \& Lapkin, S. (2000). Task-based second language learning: The uses of the first language. Language Teaching Research, 4(3), 251-274. https://doi.org/10.1177/136216880000400304

Swain, M., \& Lapkin, S. (2001). Focus on form through collaborative dialogue: Exploring task effects. In M. Bygate, P. Skehan \& M. Swain (Eds.), Researching pedagogic tasks: Second language learning, teaching and testing (pp. 99-118). London, England: Longman.

Swain, M., \& Lapkin, S. (2002). Talking it through: Two French immersion learners' response to reformulation. International Journal of Educational Research, 37(3-4), 285-304. https://doi.org/10.1016/S0883-0355(03)00006-5

Trinder, R. (2013). Business students' beliefs about language learning in a university context. English for Specific Purposes, 32(1), 1-11. https://doi.org/10.1016/j.esp.2012.06.003

Watanabe, Y., \& Swain, M. (2007). Effects of proficiency differences and patterns of pair interaction on second language learning: Collaborative dialogue between adult ESL learners. Language Teaching Research, 11(2), 121-142. https://doi.org/10.1177/136216880607074599

Weissberg, R. (2006). Scaffolded feedback: Tutorial conversations with advanced L2 writers. In K. Hyland \& F. Hyland (Eds.), Feedback in second language writing, contexts and issues. Cambridge, England: Cambridge University Press.

Whitehead, M. R. (2004). Language and literacy in the early years. Thousand Oaks, CA: SAGE.

Williams, J. (2001). The effectiveness of spontaneous attention to form. System, 29(3), 325-340. https://doi.org/10.1016/S0346-251X(01)00022-7

Zeng, G., \& Takatsuka, S. (2009). Text-based peer-peer collaborative dialogue in a computer-mediated learning environment in the EFL context. System, 37(3), 434-446. https://doi.org/10.1016/j.system.2009.01.003

\section{Copyrights}

Copyright for this article is retained by the author, with first publication rights granted to the journal.

This is an open-access article distributed under the terms and conditions of the Creative Commons Attribution license (http://creativecommons.org/licenses/by/4.0/). 